Estudios de Administración, vol. 8, N 1, 2001

\title{
Time Prices and the Demand for Primary Health Care in Chile
}

\author{
Ricardo Henríquez H. \\ Universidad de Chile
}

\begin{abstract}
In this paper we study the demand for primary health care in Chile. Particularly, we examine the demand for preventive care using a sample of urban children residents in the Metropolitan Region. Following Acton (1975), we assess the influence of time prices and several other socioeconomic and demographic factors on demand. Although not significant at conventional levels, the negative coefficient of travel time price would indicate that this nonmonetary factor (and potentially other sources of time not controlled for in this study) could act, under certain circumstances, as a money price in discouraging demand. The magnitude of the travel time price elasticity is consistent with the range of time price elasticities found in high-income countries.

The greatest impact on the probability of demand is found to be associated to food collection, nutritional status of the child and prescription of medicines. Among the nutritional conditions, undernourishment is the most important. The working status of the mother and economic variables such as earned and non-earned income do not have a relevant impact on demand.
\end{abstract}

Key words: primary health care, preventive care, nutritional status, time prices.

JEL Classification: I10. 


\section{Extracto}

En este artículo estudiamos la demanda por atención de salud primaria en Chile. En particular, examinamos la demanda por controles preventivos a partir de una muestra de niños con residencia en la zona urbana de la Región Metropolitana. Al igual que Acton (1975), evaluamos la influencia del costo del tiempo y de un conjunto de factores socioeconómicos y demográficos sobre la probabilidad de demanda. Aunque no significativo en términos convencionales, el coeficiente negativo de la variable utilizada para capturar el costo de oportunidad del tiempo de viaje (travel time price) estaría indicando que este factor no monetario (y potencialmente otras fuentes de costo de tiempo no controladas en este estudio) podrían actuar, bajo ciertas circunstancias, como un precio monetario. La magnitud de la elasticidad de la variable travel time price es consistente con el rango de elasticidades encontradas en países de alto ingreso.

El mayor impacto sobre la probabilidad de demanda se observa para las variables recolección de alimentos, estado nutricional y receta de medicamentos. De las distintas clasificaciones nutricionales del niño, el estado de desnutrición aparece como el más importante a la hora de demandar controles preventivos. La condición de empleo de la madre y las variables económicas que capturan los diferentes tipos de ingreso de los padres no tienen un impacto relevante sobre la probabilidad de demanda.

\section{Introduction}

This paper focuses on the demand for children's primary health care. In particular, it examines the demand for preventive care ${ }^{1}$ using a sample of 5,807 children residents in the urban zone of the Metropolitan Region in Chile. This population group represents an important target from a policy perspective, and parents are strongly encouraged to monitor the health status of their children on a regular basis. ${ }^{2}$ Incentives operate in the form

\footnotetext{
${ }^{1}$ The concept of preventive care refers here to regular health check-ups under well-child care activities. Accordingly, we use preventive care and health check-ups indistinctly along this paper.

${ }^{2}$ It is widely recognised that inadequate pediatric care at an early stage of development is likely to have a particular detrimental influence on the child's current and future health.
} 
of food supplements, which can be collected by parents only if the health check card of their children is up to date. ${ }^{3}$

Two previous analyses of the demand for primary health care have been carried out in Chile. The first, by Aedo (1995), concentrated on the determinants of the rate of medical visits and frequency of medical visits among children and adolescents in the three main regions of Chile. ${ }^{4} \mathrm{He}$ concluded that eligibility for nutritional programmes, age and nutritional status were the most relevant factors explaining demand. The second, by Makhlouf (1996), explored the effects of non-monetary factors and other socioeconomic and demographic variables on the demand for primary health care using a sample of individuals aged less than 18. Broadly speaking, her results were in the same line as the ones obtained by Aedo (1995).

The empirical work in both of the studies referred above was based on the third Encuesta de Caracterización Socioeconómica Nacional, CASEN 1990 (National Survey for Socioeconomic Characterisation). ${ }^{5}$ We use the same source of data but restrict the sample to individuals aged less than 15. This restriction is conceptually important as we work with children whom, in pediatric terms, correspond to individuals between the ages of 0 and 14 .

The main contribution of our work lies in the introduction of time prices into the analytical framework. We analyse whether the opportunity cost of travel time (measured by market wages) acts as a money price in discouraging demand. ${ }^{6}$ Market wages are derived from the Encuesta de Ocupación y Desocupación del Gran Santiago (The Great Santiago Employment and Unemployment Survey), an external source of information not previously used for similar purposes in Chile.

\footnotetext{
${ }^{3}$ The health check card contains records of regular health check-ups and the vaccination programme.

${ }^{4}$ Under the umbrella title "medical visits", Aedo (1995) included ambulatory services, preventive care and medical visits due to accidents and illnesses. However, the demand for these different types of health services is likely to rely on a rather dissimilar set of theoretical assumptions.

${ }^{5} \mathrm{CASEN}$ is the main source of socioeconomic information on the Chilean population available for research purposes in Chile.

${ }^{6}$ Money prices can be defined in terms of the out-of-pocket outlays derived from medical attention plus the monetary cost of transportation.
} 
Other factors are also examined. Among these, we evaluate (on a disaggregated basis $)^{7}$ the impact of the nutritional status of children on demand as well as the empirical relevance of earned and non-earned income on the decision of parents to demand preventive care for their children. Furthermore, we assess whether parents who depend largely on state provision (public subsidies) are more likely to demand preventive care given the existence of food incentives. Additionally, we examine the effect of the number of primary health centres on demand.

The paper is organised as follows. Section 2 describes the primary health care sector in Chile. In section 3 we make a brief revision of the role of time prices considering several studies on the demand for health care. Section 4 introduces the underlying theoretical model of demand utilised in the study. In section 5 we describe the empirical implementation of the model and the data, and discuss the variables examined in the estimation. In section 6 we comment the empirical results, including marginal effects and relevant elasticities. A summary and implications are presented in section 7.

\section{Primary health care in Chile: outline}

Chile's well-established primary health care network is managed locally by municipal governments. Central funds and local budgets support the operation of this network. Since municipal authorities are assumed to be in a better position to assess the needs of their respective local populations, most preventive and health promotion programmes are developed at this level.

The current model of primary health care is the result of changes introduced from mid-1970's to late in the 1980's. In this period, social policies were redefined following severe macroeconomics adjustments, structural reforms and state retrenchment. The orientation of social

\footnotetext{
${ }^{7}$ Aedo (1995) controlled for the nutritional status of the child using a dummy ( $1=$ non-normal nutritional status, $0=$ normal). We instead control for the three non-normal nutritional conditions defined by the Ministry of Health: under risk of undernourishment, undernourished and obese; the default being normal nutritional condition.
} 
expenditure changed from universal coverage towards the financing of programmes focused on the most vulnerable and deserving groups. In the health sector, the priority was given to the expansion of primary health care so that investments shifted away from hospitals in favour of primary health care facilities. As a consequence, the number of primary health centres increased in urban and rural areas, extending the coverage of basic health and nutritional programmes throughout the country, particularly for maternal and child health.

Four types of facilities define the primary health care network: rural medical stations, rural health posts, rural health centres and urban health centres. Rural medical stations are temporary sites that are periodically visited by medical staffs. Here individuals can obtain basic health care. Rural health posts, run by resident health auxiliaries, provide health promotion and preventive services to catchment areas of about 1,000 individuals. Rural health centres are operated by permanent professional and auxiliary staffs and serve populations between 2,000 and 5,000 persons. These facilities offer round-the-clock nursing and medical care for health problems of low complexity. Finally, urban health centres provide ambulatory care for general health problems eight to nine hours daily. The composition of their staff varies with the size of the locality to be attended.

Several preventive and promotional activities such as vaccination, health and nutritional education and breast-feeding promotion, along with the distribution of food products, are administered at local level under the supervision of the Ministry of Health. These activities form part of a national policy devoted to deal with the twofold problem of poor health and malnutrition among high-risk groups.

The most important preventive public intervention is the National Supplementary Feeding Programme (best known by its Spanish short-form PNAC). Under PNAC, and conditional on attendance to regular health check-ups, powdered cow milk is distributed free of charge to children between 0-2 years of age as well as to pregnant and women during lactation. A milk-cereal dry mix is also distributed to children in the 2-5 years of age group. Children at risk of malnutrition receive a supplement of rice in addition to the milk-cereal mixture.

The cost of food supplements under primary health care is not 
negligible. Currently, public expenditure on PNAC is about US\$43 million, that is, almost 9 percent of total public expenditure on health. However, the economic burden of PNAC is argued to be economically less relevant than its expected biomedical benefits on the health of target groups. Moreover, the political visibility of PNAC makes most of the efforts to curb costs almost impossible.

Undoubtedly, the impact of preventive, nutritional and health promotion activities on target groups like children has been remarkable. Infant and child health have improved substantially, with the contribution of deaths of the population aged 14 or less to total deaths dropping from 48 percent in 1960 to 5 percent in 1998. In this last year the infant mortality rate was of 10 deaths per 1,000 living births. However, although the results obtained on target groups may partly be explained by the success of the specific public programmes carried out by the Ministry of Health, public investment in basic education, potable water and sanitation has also significantly contributed to reduce the incidence of malnutrition and communicable diseases. ${ }^{8}$

\section{The role of time prices: evidence from the literature}

Since the seminal work of Becker (1965), the role of time on individual decisions has been extensively examined. Particularly, the analysis of the impact of time prices on the demand for health care has been of special interest.

Initially, the demand for a given health service was hypothesised to depend on its price, prices of alternative services, household income and tastes. These first formulations did not consider measures of time costs associated with the use of medical services and individual's characteristics such as age and education.

Acton (1973a, 1973b, 1975), Phelps and Newhouse (1974), Goldman and Grossman (1978) and Colle and Grossman (1978) modified those earlier models by allowing the inclusion of time and demographic

${ }^{8}$ A detailed discussion on the influence of these factors can be found in Castañeda (1985). 
variables. These authors also recognised the discrete nature of the decision process involved in demanding health care and, consequently, they changed the econometric approach to the problem.

Acton (1975), in his empirical study on the effect of non-monetary factors on the demand for health care conducted in New York, used a utility-maximising framework but including into the budget constraint the Becker (1965) argument that there are time costs linked with consumption activities. He focused the analysis in the role of time prices as a rationing device when insurance or public expenditure programmes reduce the outof-pocket cost of medical care. In this context, non-monetary factors should assume an increasingly important role in determining individuals' demand. The results supported his major prediction: non-monetary factors such as travel distance would work just like prices in discouraging demand. Given this prediction, Acton (1975) argued that users of free medical services would be more sensitive to waiting and travel time than would be users who pay for medical attention. He found a travel-distance elasticity of -1.4 for outpatient services, which falls in the range of money price elasticities (between -0.2 and -2.1 ) found by Rosset and Huang (1973) and Newhouse and Phelps (1974, 1976).

Phelps and Newhouse (1974) superimposed a model of the demand for health insurance on the household production model to study the impact of the coinsurance rate and the price of time on the demand for medical services. The empirical evidence presented by these authors clearly rejected the assertion that coinsurance would be irrelevant in the decision process. Furthermore, they showed that the effect of coinsurance varied across medical services in a systematic fashion depending upon the time price of the service. The predictions derived from this work were similar to that of Acton (1975): goods with proportionally high-time price components and nearly complete insurance coverage should show relatively small money price and coinsurance elasticities. Conversely, goods with a proportionally small time-price and poor insurance coverage should be more sensitive to money-price or insurance coverage changes.

Goldman and Grossman (1978) made use of an hedonic approach to study the demand for pediatric care in two health districts in New York. They argued that differences in quality were a distinguishing feature of the market for physicians' services. Consistent with this statement, they 
estimated two demand equations: one for visits and one for quality. The effect of time was captured by costing the distance travelled by users to the health centre. To value the opportunity cost of travel time these authors used Fuchs's (1968) calculations of hourly wage rates of women aged 2034 by race and years of formal schooling. The coefficient of travel cost was not statistically significant in the visit equation but well defined in the quality equation. An uncompensated (compensated) fixed travel-cost elasticity of $-0.71(-0.62)$ was found in this study.

Using a rather similar theoretical framework, Colle and Grossman (1978) analysed the determinants of utilisation of pediatric care by a national sample of American children between the ages of 1 and 5. They focused on four measures of utilisation: the probability of a physician visit, the probability of obtaining preventive care, the number of office visits to private physicians and the average quality of these visits. The theoretical justification for the inclusion of time variables in their model was derived from the assumption that parents' time would be an important input in the production function of children's health. Therefore, the relevant price for medical care should contain both a money price component and a time price component. An interesting result in this study was that the time cost of a visit for mothers who were working out of home at the time of the survey had a negative and statistically significant effect on the probability that a child obtained preventive care. Time cost elasticities where not reported.

The empirical estimations in the studies described before were based on samples of individuals belonging to high-income countries (particularly United States), but conditions in low-income countries can be substantially different. For example, it has been argued that time prices should play a more relevant role in low-income countries since health care is usually provided at zero cost at point of demand. However, a first group of studies, including the work of Heller (1982), Akin et al. $(1985,1986)$ and Birdsall and Chuhan (1986), found very small and statistically insignificant price effects. Heller (1982) found low sensitivity to time and money prices for total annual preventive visits in a rural Malaysian sample. Akin et al. (1986), on the other hand, found that travel distance and money prices were not nearly as important as determinants of the demand for medical services in a rural region of the Philippines as had 
usually been assumed. In the same line were the results for the effect of travel distance in the study by Mwabu (1994) in rural Kenya. In fact, Mwabu (1994) found travel-distance elasticities of -0.079 for government facilities, -0.3 for mission health facilities and -0.24 for private health facilities.

Conversely, a second group of studies by, among others, Dor and van der Gaag (1987), Dor, Gertler and van der Gaag (1987) and Lavy and Germain (1994) concluded that time prices played an important role in the decision to demand health care services. The results for arc travel-time elasticities obtained by Dor and van der Gaag (1987) in rural Côte D'Ivoire and by Dor, Gertler and van der Gaag (1987) in Peru showed the important rationing effect derived from the location of health facilities in these two countries.

From the results described before, the effect of time prices appears not to be straightforward. Certainly, wherever health care is provided at zero or nearly zero cost at point of consumption, the conventional role of rationing demand is likely to be assumed by time prices. However, the extent to which time prices effectively accomplish this function will depend on factors such as the organisation of the health system, particularly with respect to the spatial distribution of health care facilities, and the type of health services considered.

\section{Model}

What we describe here is a simplified version of the model developed by Goldman and Grossman (1978) to study the demand for pediatric care.

Since the sample we use is composed of children (individuals aged less than 15), the incorporation of parents' utility into the analytical framework is highly appropriate. In this sense, it is assumed that parents maximise utility $(U)$ over child health $(h)$ and consumption of a composite $\operatorname{good}(m) .{ }^{9}$ Thus,

$$
U=U(h, m) .
$$

\footnotetext{
${ }^{9}$ The composite good $(\mathrm{m})$, the numeraire, has its price normalised to 1 .
} 
It is also assumed that child health is produced through a production function whose main inputs are given by preventive care $(c)$ and a vector $(z)$ of regressors that captures, among other factors, the age of the child, child's nutritional status, mother's schooling ${ }^{10}$ and employment status of the mother. Thus,

$$
h=h(c, z) .
$$

After replacing (2) into (1) we obtain the parents' derived utility function $(V)$,

$$
V=V(c, z, m)
$$

Since parents' time is required to produce health and obtain medical care, the relevant price in the demand function for care contains both a money price component $(p)$ and a time price component $(w t)$, where $w$ stands for the hourly wage rate and $t$ is a measure of travel time. Defining $I$ as the monthly monetary income of the family and $N$ as the non-earned income of the household, the budget constraint can be written as,

$$
m+(p+t w) c=I+N
$$

Full family income $(I+N)$ is exhausted in purchasing other goods and in financing preventive care. A family's monthly monetary income $(I)$ includes the monetary earnings of the head of the household plus his/her spouse's earnings.

By solving for $m$ in (4) and replacing it in (3), we obtain,

$$
V=V[c, z, I+N-(p+t w) c]
$$

As demand equations are derived from the parents' utility function, the choice of the functional form in (5) is important. Many functional forms have been experimented but not all of them are consistent both with

\footnotetext{
${ }^{10}$ According to Colle and Grossman (1978), parents'schooling is an obvious example of a home environmental factor in the production function of children's health.
} 
empirical health care demand patterns and with the rules of rational choice. ${ }^{11}$ Basically, estimation requires a stable utility function, which implies a functional form compatible with the behavioural axiom of preference maximisation.

Utility functions linear in health related variables and quadratic in income, and utility functions linear in both health related variables and income, but in which income interacts with provider-specific attributes, have proved to be stable. In our model all the (continuous) independent variables enter the analysis in a simple linear form. Non-linearities in age were accounted for by including age squared.

Assuming that is not in the interest of doctors to induce preventive care, the relevant decision to be analysed is that of attendance/nonattendance. This decision is bounded between 0 and 1 so a limited dependent variable technique is used in the estimation. This technique allowed us to control for some of the variables frequently utilised to explain the demand for health care as well as for a set of other factors thought to be related to the demand for preventive care in Chile. All the regressors in the estimation are discussed in the next section.

\section{Empirical formulation of the model, data and variables in the estimation}

\section{A. Empirical formulation}

The simplified model described before yields a system of demand equations in which the binary outcome attendance/non-attendance to preventive care is the variable to be explained. We use a logit procedure (based on a maximum-likelihood estimator) to estimate the probability of attendance $\left(P_{a}\right)$ by the children population.

The probability of attendance is given by,

$$
P_{a}=\frac{1}{\left(1+e^{-b x}\right)},
$$

\footnotetext{
${ }^{11}$ See Mwabu et al. (1994).
} 
where $b$ is a vector of logit coefficients and $x$ a linear function of the following independent variables,

$x=x$ (child's age, food supplements eligibility, child's nutritional status, availability of domestic help, family size, earned income, non-earned income, mother's schooling, working status of the mother, money price, time price, prescription of medicines, eligibility for other public subsidies, number of primary health centres per thousand population by municipal district).

Many of the regressors above are dummies, therefore, a word of caution must be said. Basically, the use of binary variables in a regression framework allows to working with a more flexible functional form. Following Aigner et al. (1975), if the underlying regression relationship is nonlinear, the potential benefits from using dummies are clear, but not costless. However if the true relationship is linear, not only are costs due to losses in degrees of freedom but also the fitted dummy function will represent a direct loss of information.

\section{B. Data and variables in the estimation ${ }^{12}$}

The data utilised in the estimation come from the series of surveys CASEN (National Survey for Socioeconomic Characterisation). We made use of the third survey, CASEN 1990. This version collected information from a random and stratified sample of 25,793 Chilean households corresponding to 105,189 individuals along the thirteen regions of the country. We used a sub-sample of 33,886 urban individuals belonging to the Metropolitan Region, which includes the capital Santiago. Since we were interested in the children population, we restricted the analysis to the 9,750 individuals aged less than $15 .{ }^{13}$ The final sample, discounting missing values, was

\footnotetext{
${ }^{12} \mathrm{~A}$ resume with the definition of each variable and the usual descriptive statistics are provided in Tables A and B, respectively, in Appendix 1.

${ }^{13}$ See Lohr et al. (1986, chapters 4 and 5) for a detailed discussion on the
} 
composed of 5,807 observations with a fairly balance between females and males. $^{14}$

The dependent variable, preventive, is defined as a dummy $(0 / 1)$ that captures if children in the sample have attended to regular health check-ups in the three months preceding the interview. This type of health care to children is provided at primary health centres and forms part of a set of preventive activities including maternal check-ups, well-adult checkups as well as health check-ups for individuals suffering from chronic diseases like hypertension and diabetes.

Most of preventive actions devoted to children are provided to preschoolers, i.e. between 0-6 years of age. This group constitutes an important health policy target given its relatively greater vulnerability. Accordingly, every child below 7 years of age has the right to receive, free of charge, milk or other food products (depending on his nutritional status) conditional on attendance to regular health check-ups as a mean to reduce the probability of malnutrition and its undesirable sequels.

The set of explanatory variables corresponds to those included in the linear function $x$ (see previous subsection). Following the same order we have first the age of the child. The basic hypothesis here is that as children's age increases the incentive of parents to demand preventive care diminishes. We also included age squared in the estimation, as this diminution may be non-linear. As we already mentioned, only children up to 6 years of age are eligible for food supplements. Hence, it would be possible to expect a decline in the demand for preventive care per child once he/she has passed the threshold of six years of age.

On the other hand, since food supplementation constitutes an incentive for parents to take their children to health check-ups, we included a dummy $(0 / 1)$ which accounts for food collection. The idea is to assess the impact of food supplements on the disposition of parents to demand preventive care for their children.

Child's nutritional status is another important factor considered in the analysis. CASEN 1990 asked each household in the sample about the

different nature of the demand for physician visits by children and adults.

${ }^{14}$ Since each individual in the sample population did not have equal probability of selection, each observation was weighted by the reciprocal of its probability of selection (probability weight) to obtain more efficient estimates. 
nutritional status of the children following the classification provided by the Ministry of Health, that is: normal, under risk of undernourishment, undernourished and obese. The percentage response to this question is quite high given that the information is easily attainable. After each health check-up parents are provided with a record containing the anthropometric measures of the child (weight, height and head growth) and his/her nutritional condition. To capture the effect of this biomedical factor we use three dummies: biorisk1 for under risk of undernourishment, biorisk 2 for undernourished and biorisk3 for obese; the default being normal nutritional status. It is expected that children with nutritional problems are more likely to demand preventive care. ${ }^{15}$

We also observed the effect of the availability of domestic help on the demand for preventive care. Since mothers are generally responsible for taking children to health check-ups (normally a very time-consuming activity in Chile), and given that they are also usually in charge of most of the domestic chores, the possibility of some kind of domestic support could make the attendance to health check-ups more probable. A dummy $(0 / 1)$, domestic help, accounts for this fact.

Family characteristics, frequently incorporated in many of the studies on the demand for health care, are also empirically examined in this study. We use the family size to control for the fact that, ceteris paribus, larger families may be subject to a negative income effect so they could be less prone to demand a voluntary (non-induced) health service such as preventive care. ${ }^{16}$

To control for the effect of income on parents' decisions we use two income categories: earned and non-earned income. These two continuous variables are measured in Chilean pesos (Ch.\$) of $1990 .{ }^{17}$ The first, which enters the estimation in per capita terms, includes all those

\footnotetext{
${ }^{15}$ In turn, child's nutritional status depends on a complex set of intervening factors. Popkin (1974) and Popkin and Solon (1976) make a detailed discussion on this point using a sample of children from the Cebu Island in the Philippines.

${ }^{16}$ Ceteris paribus, as the family size increases a reduction in income per person may be verified and, therefore, a reduction in the use of medical services. For instance, according to Colle and Grossman (1978), an increment in the number of children in a family increases the cost of raising their average level of health and lowers the quantity of health care demanded.

${ }^{17}$ The average observed exchange rate during 1990 was of Ch.\$309.4 per US\$ 1 dollar.
} 
resources obtained from the participation in the labour market: income from the principal job, pensions, public subsidies, in kind transfers, etc. The second, also defined in per capita terms, derives from sources other than the labour market: house rental, savings, shares, bonds and others. If preventive care is assumed to be a normal good, one should expect a positive correlation with non-earned income. The effect of earned income is not clear because it depends on the time intensity of preventive care relative to other goods and services. In any case, since preventive care is provided free of charge, earned income should work more like an income effect [see Acton (1975) p.609].

Several studies have remarked the relevance of mothers' schooling as a positive factor affecting the efficiency in the production of healthy children. ${ }^{18}$ Basically, a mother with a higher level of education is supposed to be better equipped to assess the benefits of keeping a regular programme of health check-ups for their children as well as providing them with, among others, healthy food (e.g. breast-feeding at an early stage) and a healthy home environment. In this context, we included the continuous variable mother's schooling, which stands for the years of formal schooling completed by mothers. ${ }^{19}$

Another relevant factor in the analysis is the employment status of the mother. Following Popkin and Solon (1976), the working status of the mother and other time household constraints affect the use of health, nutrition and other welfare-related social services. The essential point is that mothers who work out of home may have less time available to take their children to health check-ups. Commonly, preventive care in Chile is provided during the mornings from Mondays to Fridays under a restricted timetable. Therefore, mothers in the labour market may face difficulties to accomplish with the programme of visits recommended by doctors. A dummy $(0 / 1)$ variable, mother at work, is included in the estimation to account for the working status of the mother.

Due to data restrictions, the money price $(p)$ of preventive care

${ }^{18}$ See for example Kessner (1977), Inman (1976), Edwards and Grossman (1977), Friedman and Leibowitz (1975), and Slesinger (1976).

${ }^{19}$ As a reference, under the Chilean educational system 8 years of schooling represent completed basic education, 12 years of schooling imply completed secondary education and 18 years of education are usually associated to completed technical or university degree. 
was set to zero for all the observations in the sample. ${ }^{20}$ However, this obligatory procedure is consistent with the fact that preventive care is provided free of charge to publicly insured. Private health insurance plans, on the other hand, allow their affiliates at least two free health check-ups per year as part of the benefits. ${ }^{21}$ Besides, the privately insured can also access public health facilities paying a very reduced fee. In our sample 78 percent of the children who attended preventive care had public insurance coverage and 14 percent corresponded to children whose parents were covered under private health insurance plans. The remaining 8 percent was composed of children whose parents had no type of health insurance and for children whose parents were members of the armed forces. Children with no type of health insurance can access primary health care at zero cost in public facilities, while children whose parents belong to the armed forces are completely covered by the welfare programmes of the respective armed institution.

As mentioned in the introduction, an important objective of this study is the assessment of the effect of time prices on the demand for preventive care. In words of Coffey (1983 p.412), the value of time in an activity is the opportunity cost of time in alternative activities. Thus, the value of market time, given by the wage rate, is usually taken as a reference for the value of non-market or consumption time. For individuals who do not participate in the labour market the reservation wage should be utilised, i.e. the wage that would attract them to take a job in the labour market. CASEN 1990 asked each individual the time (in minutes) travelled to the closer health centre. Considering that mothers are typically responsible for the child, we defined the opportunity cost of travel time in terms of mother's wage rate $(w)$. Unfortunately CASEN 1990 does not record information on individuals' wages. Therefore, we derived wages from the Encuesta de Ocupación y Desocupación del Gran Santiago, June 1990 (The Great Santiago Employment and Unemployment Survey). This survey is conducted quarterly since 1960 and collects information on the

${ }^{20}$ As indicated in footnote 6 , the money price of medical care also includes the cost of transportation. Therefore, in setting $p$ equal zero we assumed, implicitly, that transportation costs were zero.

${ }^{21}$ On average, the number of health check-ups fluctuates between 1 and 2 per person per year. 
employment status and wages of individuals residents in the Great Santiago along with certain socio-demographic attributes such as age, sex and level of schooling. From this data set we calculated the average hourly wage rate of females by age and years of schooling completed. We used nine age categories (excluding females between 0-13 years of age because they, by law, are not allowed to participate in the labour market) and four educational categories: none (zero years of schooling), primary (8 years of schooling), secondary (12 years of schooling) and post-secondary (more than 13 years of schooling). ${ }^{22}$

CASEN 1990 identifies each individual in the sample according to his/her relationship with the head of the household, thus we were able to assign each mother the corresponding average wage rate. Certainly, as observed by Goldman and Grossman (1978), even if women did not work in the labour force, this procedure would be justified if the value of nonmarket time depended on age and years of formal schooling. Finally, we constructed the variable travel time price by multiplying the average hourly wage rate by the reported travel time (transformed to hours). This variable entered the estimation in logarithmic terms.

The last three variables in the linear function $x$ are prescription of medicines, eligibility for other public subsidies, and the number of primary health centres per thousand population in the respective municipal district. We included a dummy (0/1) accounting for prescription of medicines because there is some evidence that people assign a high level of importance to the fact of being prescribed. Scarpaci (1989) points out that a careful examination from the doctor and the prescription of medicines constitute the most relevant factors influencing Chilean users' perception about the quality of medical care.

Being eligible for other public subsidies is introduced as a means to observe if parents that depend largely on state provision are more likely to demand a free provided health service like preventive care. We used a dummy (0/1), welfare, which takes the value 1 if parents are beneficiaries of any kind of public subsidies (other than food supplements) and 0 otherwise.

\footnotetext{
${ }^{22}$ As seen in section 4.3, Goldman and Grossman (1978) utilised the same strategy. In fact, they used Fuchs's (1968) calculations of hourly wage rates of women aged 24-34 by race and years of formal schooling completed.
} 
Finally, we incorporated the continuous variable health centres to account for differences in access to primary health care. This variable records the number of primary health centres per thousand population operating in each municipal district. Since the location and number of these facilities depend to a large extent on the political will of the government, the potential risk of simultaneity in the interaction between demand and supply forces is not likely to be present. ${ }^{23}$

Logit estimates of the probability of attendance to preventive care by the sample of urban children in the Metropolitan Region of Chile, along with marginal effects and elasticities, are presented and discussed in the next section.

\section{Empirical results}

\section{A. Logit estimates}

Estimates of the logit model are presented in Table 1. As expected, both age and age squared are significant at 5 percent. The negative and positive signs of the coefficients of these two variables, respectively, confirm that the probability of attendance to preventive care is not linear in age. One could advance at least two possible explanations for this quadratic relationship. First, from a biomedical point of view children become less vulnerable as they grow so that free provided health check-ups and food supplementation become less effective. Furthermore, since the effectiveness of such public interventions decreases with age they are normally restricted to children under 7 , reducing in this way the access of older children. Second, as parents get more knowledge and experience to cope with, let us say, the common medical problems affecting their children, the dependence on preventive and other source of medical care is in some extent attenuated. As a consequence, parents would tend to

\footnotetext{
${ }^{23}$ Colle and Grossman (1978) followed a different strategy and included in the empirical equation the number of physicians per hundred population interacted with the size of place of residence. Basically, they tried to estimate de size of the availability effect in the market for pediatric care. Pauly (1978) argued that the availability effect would due in part to demand manipulation by physicians in the presence of imperfect information.
} 
demand relatively less health care for their children.

The impact of food supplements on the probability of attendance to preventive care is clear. The positive and statistically significant coefficient of food collection reflect that the distribution of powdered cow milk to children aged less than 2 and a milk-cereal mix to children in the 25 years of age group (as well as a supplement of rice to children at risk of malnutrition), constitutes a powerful incentive for parents to demand preventive care for their children. ${ }^{24}$ Indeed, this result is consistent with the one obtained for age. Since children are eligible for food supplements only up to 6 years of age, it is reasonable to have found a negative tendency to demand preventive care as children's age increases. ${ }^{25}$

Table 1

Probability of attendance to preventive care by children

\begin{tabular}{|c|c|c|c|c|}
\hline $\begin{array}{l}\text { Number of observations } \\
\text { Prob }>\text { chi2 } \\
\text { Pseudo } \mathrm{R}^{2}\end{array}$ & $\begin{array}{l}=5,807 \\
=0.000 \\
=0.275\end{array}$ & $\begin{array}{l}\text { Wald } \chi^{2} \\
\text { Log Likel }\end{array}$ & $\begin{array}{l}=66 \\
=-2,01\end{array}$ & \\
\hline & $\begin{array}{l}\text { LOGIT } \\
\text { COEFFICIENT }\end{array}$ & $\begin{array}{l}\text { ROBUST } \\
\text { STD. } \\
\text { ERRORS }\end{array}$ & $\begin{array}{l}\text { ASYMPTOTIC } \\
t \text {-RATIO }\end{array}$ & $\mathrm{P}>|t|$ \\
\hline Constant & -0.1381 & 0.3592 & -0.385 & 0.701 \\
\hline Age & -0.3673 & 0.0463 & -7.927 & 0.000 \\
\hline Age squared & 0.0079 & 0.0038 & 2.095 & 0.036 \\
\hline Food collection & 0.7926 & 0.1242 & 6.382 & 0.000 \\
\hline Biorisk1 & -0.2288 & 0.2590 & -0.883 & 0.377 \\
\hline Biorisk2 & 0.7899 & 0.2554 & 3.092 & 0.002 \\
\hline Biorisk3 & 0.2046 & 0.2848 & 0.718 & 0.473 \\
\hline Domestic help & 0.8156 & 0.2554 & 3.193 & 0.001 \\
\hline Family size & -0.0850 & 0.0414 & -2.050 & 0.040 \\
\hline Earned income $e^{\mathrm{a}}$ & $6.65 \mathrm{e}-07$ & $7.18 \mathrm{e}-07$ & 0.927 & 0.354 \\
\hline Non-earned income $e^{\mathrm{a}}$ & $4.04 \mathrm{e}-06$ & $7.45 \mathrm{e}-06$ & 0.543 & 0.587 \\
\hline
\end{tabular}

\footnotetext{
${ }^{24} \mathrm{~A}$ detailed analysis of the impact of food supplements on pre-schoolers in the capital of Chile, Santiago, can be found in Muchnik and Vial (1990).

${ }^{25}$ Breakdowns by age $(0-2,3-5$ and $6-14)$ show that the probability of attendance is greater for the first group (0-2), declines slightly in the second (3-5) and decreases importantly in the third (6-14).
} 


\begin{tabular}{|l|c|c|c|c|}
\hline Mother's schooling & 0.0396 & 0.0162 & 2.444 & 0.015 \\
\hline Mother at work & -0.1638 & 0.1191 & -1.375 & 0.169 \\
\hline $\begin{array}{l}\text { Travel time price } \\
\text { Prescription } \\
\text { medicines }\end{array}$ & -0.0969 & 0.0596 & -1.626 & 0.104 \\
\hline $\begin{array}{l}\text { Welfare } \\
\text { Health centres }\end{array}$ & 0.1817 & 0.1322 & 8.838 & 0.000 \\
\hline
\end{tabular}

${ }^{\mathrm{a}}$ Reported in Chilean \$ (Ch.\$)

${ }^{\mathrm{b}}$ Chilean $\$$ (Ch.\$) per hour (in logarithmic terms)

From the set of three dummies accounting for the nutritional status of the child, only biorisk2 (which stands for undernourished) proved to be significant. ${ }^{26}$ This particular result was expected since mothers of children facing malnutrition are strongly encouraged to follow a strict calendar of periodical visits in order to control the nutritional evolution of their children. On the other hand, in explaining the low significance of biorisk3 (reflecting obese children) one could invoke both technical and intuitive reasons, respectively. First, the calendar of visits recommended by doctors to obese children is less intensive and, second, obesity is not always associated with an illness by parents. ${ }^{27}$ This lack of awareness could reduce even more the frequency of health check-ups by this population group.

The positive effect of domestic help on the probability of demanding preventive care is confirmed by our results. In some extent, the availability of some kind of domestic support provides a substitute for mothers' own time in making household's chores and caring for children. On this basis, mothers could dispose more time to take advantage of the free provision of preventive care and food supplements. Although the number of people willing to work in domestic activities has dramatically declined along the years in Chile, households can still obtain domestic help

\footnotetext{
${ }^{26}$ Although biorisk1 and biorisk3 were not statistically significant, they (including biorisk2) proved to be jointly significant at 5 percent. $\chi^{2}[3]=11.05$; $p>\chi^{2}[3]=0.0115$.

${ }^{27}$ Lately, several studies have reported an increasing prevalence of obesity among Chilean children. This new nutritional context should imply a careful revision of the National Supplementary Feeding Programme, PNAC.
} 
at a reasonable cost.

The result for family size was the a priori predicted and it is consistent with findings in similar studies [e.g., see Wedig (1988)]. The negative effect of larger families probably derives from its impact on per capita income. ${ }^{28}$ In this context, an increasing family size may reduce medical consumption per person. Furthermore, even though preventive care is provided free of charge at point of demand, total out-of-pocket expenditures are likely to be positive due to transportation costs. The presence of these costs, not recorded by our data, could turn the access to medical care more difficult for members of larger families.

The two categories of income, earned and non-earned income, are unimportant determinants of the probability of attendance to preventive care. Since we assumed preventive care as a normal good, the positive coefficient of non-earned income was expected. However, the low significance and low magnitude of its coefficient indicate that income from sources other than the labour market plays a small role in the decision of parents to demand preventive care for their children. By the same token, the positive but not statistically significant coefficient of earned income gives partial support to the hypothesis that when medical services like health check-ups are provided free of charge, earned income would work more like an income effect on individuals' consumption. ${ }^{29}$

The years of formal education of the mother, captured by mother's schooling, influence positively (and significantly) the probability of demanding preventive care. Undoubtedly, the free provision of these medical services, along with informational campaigns directed to mothers, represents the explicit recognition of the importance of prevention on child's health. However, the degree to which mothers are more or less conscious about this well documented fact presumably depends on their

\footnotetext{
${ }^{28}$ The use of family size allowed us to observe the income effect of larger families on the probability of demand. Other studies have utilised the family composition and examined the effect of the number of adults and children on the probability of demand. For example, Dor and van der Gaag (1987) conclude that more adults in the family can reduce the probability of demanding medical care since adults normally provide home care.

${ }^{29}$ In contrast, Lohr et al. (1986) found that, among children, a higher income had a significant positive effect on the probability of seeking medical care for two preventive services: vision examination and general medical examination.
} 
educational level.

The dummy variable accounting for the working status of mothers (mother at work) proved to be not statistically significant at conventional levels. However, it is worth to notice the potential impact of mothers' time taken away from household activities on the health and nutritional status of the child. In essence, when mothers participate in the labour market the amount of time available for household activities (particularly for the very time-consuming ones such as child care and breast-feeding) is likely to decline. Likewise, mothers who spend large hours working out of home are frequently less able to collect food on a regular basis from supplementary feeding programmes. Indeed, and following Popkin and Solon (1976), the magnitude of the effects derived from the labour participation of the mother on the nutritional status and health of the child, will be determined by the extent to which mothers' job is compatible with child care, by the quality of child care available from substitutes, and by the availability and quality of both social services and market purchased goods, which provide substitutes for mothers' time.

An important objective of this study was the examination of the effect of time prices. Particularly, the value of travel time was hypothesised to act as an alternative mechanism to regulate demand given the absence of money prices [see Acton (1975)]. This presumption is partly supported by our results. In fact, from Table 1 we observe that, although negative, the coefficient of travel time price is not statistically significant (at least for significance levels below 10 percent). Two factors could help to explain this result. First, the reported travel time (in minutes) presented a relatively low variance across observations. This low variance probably reflects the policy to locate primary health centres close to users' residence. Second, our procedure consisting in assigning a wage rate to females (mothers) who were out of the labour market based on age and years of schooling, could be inadequate to capture appropriately their reservation wages. For example, if the reservation wage falls during pregnancy or during the breast-feeding period, the wages assigned to mothers in these conditions could overestimate their relevant reservation wages. To account for this possibility, it would have been necessary to control for the pregnant (or breast-feeding) status of females in the original data on wages (The Great Santiago Employment and Unemployment 
Survey). Unfortunately, this survey does not record information on these conditions.

The well-defined coefficient sign of prescription of medicines conforms to the a priori expectations. The highly significance of this variable tells us that parents assign great value to the fact of receiving prescriptions for their children when taking them to health check-ups. This is so even though medicines are not free for all. On the other hand, the positive result for welfare (although less well defined), indicates that parents who are recipients of public subsidies are more likely to demand preventive care for their children. The gratuity of preventive care seems to constitute a strong incentive for parents who depend largely on state provision. Colle and Grossman (1978) obtained the same effect for their dummy accounting for welfare programmes' recipients in the particular case of preventive care. However, they made clear that beneficiaries of welfare programmes could find substantial barriers to see specialists or to make a relatively large number of pediatric visits to physicians in private practice.

Although not statistically significant, the result for health centres deserves a couple of comments. First, the availability of primary health centres appears to play a small role in the decision of parents to take their children to preventive care. Second, the negative coefficient of this variable is likely to reflect the rather complex nature of the relationship between supply and individuals' demand behaviour. Probably, municipal districts with a relatively higher number of primary health facilities are also those who face a greater pressure for the different types of medical attention provided under primary health care. This pressure usually derives in large queues so parents facing excessive waiting time could be less willing to demand preventive care for their children from their local health facilities.

\section{B. Marginal effects and elasticities}

Marginal effects and estimates of the elasticities are shown in Table 2. ${ }^{30}$

\footnotetext{
${ }^{30}$ The derivation of the formula to calculate the elasticities is presented in
} 
The empirical equation utilised to estimate the elasticities was specified the same way as that of Table 1 . We calculated marginal effects because they permit to observe the impact of changes in the explanatory variables on the probability of attendance. The greatest impact on the probability of demanding preventive care is produced by food collection, the condition of being undernourished (biorisk2), domestic help and prescription of medicines.

The delivery of food supplements increases the probability of attendance in 7.5 points. Aedo (1995) obtained a similar result and as a policy recommendation suggested extending the eligibility for food supplementation beyond the threshold of 6 years of age. However, the potential impact of a policy like this is moot. Basically, food supplements are intended to cover food requirements during the most vulnerable years of children and this is consistent with the threshold above mentioned. Furthermore, the impact of this measure on costs probably would make it unaffordable for a middle-income country like Chile.

Table 2

Marginal effects from logit and elasticity of change in probability

\begin{tabular}{|c|c|c|}
\hline $\begin{array}{l}\text { Number of observations } \\
\text { Prob }>\text { chi2 } \\
\text { Pseudo } \mathrm{R}^{2}\end{array}$ & $\begin{array}{l}=5,807 \\
=0.000 \\
=0.275\end{array}$ & $\begin{array}{l}=1,005.05 \\
=-2,015.10\end{array}$ \\
\hline & $\begin{array}{l}\text { MARGINAL } \\
\text { EFFECT }\end{array}$ & $\begin{array}{c}\text { ElASTICIY OF CHANGE } \\
\text { IN PROBABILITY (AT THE MEAN) }\end{array}$ \\
\hline Age & -0.0349 & -1.8983 \\
\hline Age squared & & \\
\hline Food collection & 0.0754 & 0.1511 \\
\hline Biorisk1 & -0.0217 & -0.0057 \\
\hline Biorisk2 & 0.0751 & 0.0152 \\
\hline Biorisk3 & 0.0194 & 0.0055 \\
\hline Domestic help & 0.0776 & 0.0147 \\
\hline Family size & -0.0080 & -0.2986 \\
\hline Earned income $^{\mathrm{a}}$ & $6.33 \mathrm{e}-08$ & 0.0164 \\
\hline Non-earned income ${ }^{\mathrm{a}}$ & $3.85 \mathrm{e}-07$ & 0.0078 \\
\hline
\end{tabular}

Appendix 2. 


\begin{tabular}{|l|c|c|}
\hline Mother's schooling & 0.0037 & 0.2686 \\
\hline Mother at work & -0.0155 & -0.0384 \\
\hline Travel time price & -0.0092 & -0.2976 \\
\hline Prescription of medicines & 0.1112 & 0.1067 \\
\hline Welfare & 0.0172 & 0.0805 \\
\hline Health centres & -0.1880 & -0.0393 \\
\hline
\end{tabular}

${ }^{a}$ Reported in Chilean $\$(C h . \$)$

${ }^{\mathrm{b}}$ Chilean $\$$ (Ch.\$) per hour (in logarithmic terms)

The impact of malnutrition on the probability of attendance is quite strong. While being under risk of undernourishment (biorisk1) increments the probability of attendance in 2.1 points, being undernourished (biorisk2) increases this probability in 7.5 points. These results support the hypothesis that the more severe the nutritional condition of the child the higher the probability of demanding preventive care.

The availability of domestic help increases the probability of demand in 7.7 points. As we noted before, taking children to health checkups is a very time-consuming activity which, in some extent, competes with other household activities. Therefore, the possibility of some kind of domestic support can alleviate the pressure on mothers' time making possible for them to accomplish with regular health check-ups for their children.

Prescription of medicines has a significant impact on demand. In fact, if parents are given prescriptions for their children the probability of attendance increases in 11.1 points. This result was highly foreseeable because both public and private health insurance offer a very limited coverage for costs derived from prescriptions.

In examining the magnitude of the elasticities we observe that the probability of demanding preventive care appears to be inelastic with respect to the nutritional status of the child. A similar conclusion applies to domestic help, earned and non-earned income, working status of the mother (mother at work) and the fact of being recipient of public subsidies (welfare).

Our result for the earned-income elasticity differs substantially from those observed in low-income countries. However, it must be noticed that Chile is a middle-income country so many of the circumstances prevalent in low-income countries do not strictly apply in the Chilean 
context. The magnitude of the earned income elasticity found in our study (0.016) approaches more closely the results for income elasticities observed in high-income countries (values between 0.2 and 0.3 ).

On the other hand, the demand for preventive care seems to be relatively elastic with respect to age. This result derives from the already noted fact that the eligibility for food supplements is associated to children's age.

Finally, a rather similar range of elasticities is observed for the variables family size (-0.29), mothers' schooling (0.26) and travel time price (-0.29). The magnitude of the travel time price elasticity is highly consistent with the relatively low value obtained for the earned income elasticity (following the relationship between price and income elasticity derived from the Slutzky decomposition) and with the range of price elasticities found in high-income countries $(-0.2$ to -2.1$)$.

\section{Summary and implications}

As noted by Bitrán and McInnes (1993), the analysis of the demand for preventive care requires a rather complex, yet mostly unexplored, set of assumptions about individual's behaviour. Considering this theoretical shortcoming, we used a simplified version of the utility maximisation model developed by Goldman and Grossman (1978) to study the demand for pediatric care.

Besides the common set of variables utilised in previous empirical studies on the demand for health care by children in Chile, the equation model estimated here included several explanatory variables not examined before. Particular importance was given to time prices, captured by the opportunity cost of travel time. Other relevant controls incorporated were the nutritional status of children (analysed on a disaggregated basis), family size and earned and non-earned income. We also assessed the effect of prescription of medicines, the condition of being recipient of public subsidies and the number of health centres on the probability of demand.

The empirical results shed light on some interesting points. First, given the spatial distribution of health centres, travel time would not be a relevant determinant of the decision to demand preventive care. Probably a 
measure like waiting time would be more appropriate to capture the role of time. Since waiting time has been recognised as a main problem by users, its potential contribution to the non-monetary cost of medical care could be significant. Unfortunately CASEN 1990 did not collect information on this particular source of time.

A second important point, from a policy perspective, derives from the combined effect of age and food collection. Since the demand for preventive care is quite sensitive to age and given that food supplementation has been found to be more effective at an early stage of development and growth of children, it would be recommendable to consider a reduction in the age threshold for food supplements eligibility. ${ }^{31}$ A measure like this would allow authorities to focus resources (food and physician hours at primary health centres) on those children who are more vulnerable to nutritional deficits.

Certainly a reduction in the age threshold for food eligibility could imply, in turn, a reduction in the rate of preventive care by older children. However, this indirect effect could be overwhelmed by providing free prescriptions (or at a reduced price) to users. The empirical support for a policy like this is given by the positive correlation found between prescription of medicines and probability of demand. Of course, the costs of such a policy could be substantial, but probably lower than the political costs of reducing the age threshold without a complementary measure.

A third and potentially relevant aspect we can observe from the results in Table 1, comes from the negative although not statistically significant coefficient of health centres. If, as we discussed in the previous section, a higher number of health centres can be associated to a higher demand, parents facing problems to get an opportune medical attention for their children could consider to transfer their demands to other municipal districts creating a new focus of potential congestion. In a policy perspective, therefore, the number and spatial distribution of health centres should not depend, even partly, on the political will of the authorities. Instead, they should obey to demand criteria and resources constraints.

\footnotetext{
${ }^{31}$ The study by Torche et al. (1995) supports this recommendation. They concluded that the impact of the National Supplementary Feeding Programme, PNAC, is greater in children under 3 years of age.
} 


\section{Appendix 1}

Table A

Variable definitions

\begin{tabular}{|c|c|}
\hline VARIABLES & \\
\hline \multicolumn{2}{|l|}{ Dependent variable: } \\
\hline Preventive & $\begin{array}{l}\text { Dummy variable: } 1=\text { children have attended to regular health } \\
\text { check-ups in the three months preceding the survey, } \\
0=\text { otherwise. }\end{array}$ \\
\hline \multicolumn{2}{|l|}{ Explanatory variables: } \\
\hline$x_{1}$ & $\begin{array}{l}\text { Continuous variable accounting for the age of the child in } \\
\text { years. }\end{array}$ \\
\hline Food collection & $\begin{array}{l}\text { Dummy variable: } 1=\text { parents collected food supplements, } \\
0=\text { otherwise. }\end{array}$ \\
\hline Biorisk1-Biorisk3 & $\begin{array}{l}\text { Set of three dummies reflecting child's nutritional status: } \\
\text { biorisk } 1 \text { for under risk of undernourishment, biorisk } 2 \text { for } \\
\text { undernourished, and biorisk } 3 \text { for obese. The default being } \\
\text { normal nutritional status. }\end{array}$ \\
\hline Domestic help & $\begin{array}{l}\text { Dummy variable: } 1=\text { the household counts with some kind of } \\
\text { domestic support, } 0=\text { otherwise. }\end{array}$ \\
\hline Family size & Continuous variable indicating the size of the family group. \\
\hline Earned income & $\begin{array}{l}\text { Per capita monthly monetary income of the family expressed } \\
\text { in Chilean pesos (Ch.\$) of 1990. It includes income from the } \\
\text { principal job, pensions, public subsidies and in kind transfers. }\end{array}$ \\
\hline Non-earned income & $\begin{array}{l}\text { Income derived from sources other than the participation in } \\
\text { the labour market. It is expressed in Chilean pesos (Ch.\$) of } \\
1990 \text { and includes: house rental, savings, shares, bonds, etc. }\end{array}$ \\
\hline Mother's schooling & $\begin{array}{l}\text { Continuous variable standing for the years of formal } \\
\text { schooling completed by the mother. }\end{array}$ \\
\hline Mother at work & $\begin{array}{l}\text { Dummy variable: } 1=\text { mother is working at the market place, } \\
0=\text { otherwise. }\end{array}$ \\
\hline Travel time price & $\begin{array}{l}\text { Natural logarithm of the variable resulting from multiplying } \\
\text { the reported travel time by the average hourly wage rate } \\
\text { (Ch.\$ per hour). }\end{array}$ \\
\hline $\begin{array}{l}\text { Prescription } \\
\text { medicines }\end{array}$ & $\begin{array}{l}\text { Dummy variable: } 1=\text { children were prescribed with } \\
\text { medicines, } 0=\text { otherwise. }\end{array}$ \\
\hline Welfare & $\begin{array}{l}\text { Dummy variable: } 1=\text { recipient of public subsidies other than } \\
\text { food supplements, } 0=\text { otherwise. }\end{array}$ \\
\hline Health centres & $\begin{array}{l}\text { Continuous variable standing for the number of public health } \\
\text { centres per thousand population in the respective municipal } \\
\text { district. }\end{array}$ \\
\hline
\end{tabular}


Table B

Descriptive statistics $(N=5,807)$

\begin{tabular}{|l|c|c|c|}
\hline VARIABLES & \% OF OBSERVATIONS $=1$ & MEAN & ST. DEVIATION \\
\hline Dependent variable: & & & \\
\hline Preventive & 18.92 & & \\
\hline Explanatory variables: & & & \\
\hline Age & & & \\
\hline Food collection & 25.62 & & \\
\hline Biorisk1 & 3.34 & & \\
\hline Biorisk2 & 2.58 & & \\
\hline Biorisk3 & 3.61 & & \\
\hline Domestic help & 2.42 & & \\
\hline Family size & & $33,123.94$ & $56,676.54$ \\
\hline Earned income & & $2,593.63$ & $6,102.01$ \\
\hline Non-earned income & & 9.11 & 3.91 \\
\hline Mother's schooling & 31.58 & & \\
\hline Mother at work & & & \\
\hline Travel time price & & & \\
\hline Prescription of medicines & 59.53 & & \\
\hline Welfare & & & \\
\hline Health centres & & & \\
\hline
\end{tabular}

${ }^{\mathrm{a}}$ Reported in Chilean $\$(\mathrm{Ch} . \$)$

${ }^{\mathrm{b}}$ Chilean \$ (Ch.\$) per hour (in logarithmic terms) 


\section{Appendix 2}

\section{Derivation of elasticities in a logit model}

Under discrete choice models the usual formula to calculate elasticities, defined as the percentage change in variable $\mathrm{Y}$ with respect to a percentage change in another variable $\mathrm{X}$, is given in probabilistic terms. Since binary logit is a special case of multinomial logit, the probability of success can be defined as follows,

$$
P_{j}=\frac{e^{\beta x_{j}}}{1+e^{\beta^{\prime} x_{j}}}
$$

where $\beta$ is the parameter vector and $x$ a vector of regressors. Subscript $j$ identifies the alternative associated to success (in our particular case, the attendance to preventive care). A general expression for the elasticity $(\varepsilon)$ can be therefore expressed as,

$$
\varepsilon=\frac{\partial P_{j}}{\partial x_{k}} \frac{x_{k}}{P_{j}}
$$

The partial derivative in the right hand side of (2) corresponds to the marginal effect of variable $k$ of vector $x$ on the probability of success. Using (1) the marginal effect is given by,

$$
\frac{\partial P_{j}}{\partial x_{k}}=\frac{\left(1+e^{x^{\prime} \beta}\right)\left(e^{x^{\prime} \beta}\right) \beta_{k}-e^{x^{\prime} \beta}\left(e^{x^{\prime} \beta}\right) \beta_{k}}{\left(1+e^{x^{\prime} \beta}\right)^{2}}=\frac{e^{x^{\prime} \beta}}{\left(1+e^{x^{\prime} \beta}\right)\left(1+e^{x^{\prime} \beta}\right)} \beta_{k} .
$$

By replacing the expression for $P_{j}$ shown in (1) in (3), the marginal effect reduces to,

$$
\frac{\partial P_{j}}{\partial x_{k}}=P_{j}\left(1-P_{j}\right) \beta_{k}
$$

The elasticity is obtained simply by completing the expression in (2) using (4). Doing this we finally get, 


$$
\varepsilon=\left(1-P_{j}\right) \beta_{k} x_{k}
$$

The formula in (5) may be calculated using the means of the variables in vector $x$ and the predicted probability $\left(P_{j}\right)$, or as an average of all individual elasticities. We opted for the first method.

\section{REFERENCES}

Acton, J.P. (1973a). "Demand for Health Care Among the Urban Poor with Special Emphasis on the Role of Time". Memorandum R-1151OEO/NYC. Santa Monica, CA: Rand Corporation.

(1973b). "Demand for Health Care when Time Prices Vary More than Money Prices". Memorandum R-1189-OEO/NYC. Santa Monica, CA: Rand Corporation.

(1975). "Nonmonetary Factors in the Demand for Medical Services: Some Empirical Evidence". Journal of Political Economy 83: 595614.

AEDO, C. (1995). "Determinantes de la Tasa de Consultas de Salud del Niño y del Adolescente". Revista de Análisis Económico. Vol. 10 (1): 53-70. ILADES/Georgetown University.

Aigner, D.J., A.S. Goldberger, and G. Kalton (1975). "On the Explanatory Power of Dummy Variable Regressions". International Economic Review. Vol. 16 (2): 503-510.

AKIn, J.S., C. GRIFfin, D.K. GuilkeY, and B.M. Popkin (1985). "The Demand for Primary Health Services in the Third World". Totowa, N.J.: Rowan and Allenheld. 
(1986). "The Demand for Primary Health Care Services in the Bicol Region of the Philippines". Economic Development and Cultural Change 34 (4): 755-82.

BECKER, G.S. (1965). "A Theory of Allocation of Time”. Economic Journal 75: 493-517.

Birdsall, N., and P. Chuhan (1986). "Client Choice of Health Treatment in Rural Mali". Washington, D.C.: Population and Human Resources Department, World Bank.

BItRÁN, R., and D.K. MCInNes (1993). "The Demand for Health Care in Latin America: Lessons from the Dominican Republic and El Salvador". Washington, D.C.: Economic and Development Institute, World Bank.

Castañeda, T. (1985). "Determinantes del Descenso de la Mortalidad Infantil en Chile: 1975-1983”. Cuadernos de Economía 66: 195-214. Pontificia Universidad Católica de Chile.

Coffey, R. (1983). "The Effect of the Time Price on the Demand for Medical Care Services". Journal of Human Resources 3: 407-424.

Colle, A.D., and M. Grossman (1978). "Determinants of Pediatric Care Utilisation”. Journal of Human Resources 13 (supplement): 115-158.

Cretin, S., E.B. KeEler, A.P. Williams, and Y. Shi (1988). "Factors Affecting Town-Countryside Differences in the Use of Health Services in Two Rural Counties in Sichuan". Santa Monica, CA: Rand Corporation.

Dor, A., P. Gertler, and J. VAN DER GAAG (1987). "Non-Price Rationing and Medical Care Provider Choice in Côte d'Ivoire". Journal of Health Economics 6: 291-304.

Dor, A., and J. VAN DER GAAG (1987). "The Demand for Medical Care in Developing Countries. Quantity Rationing in Rural Côte d'Ivoire". LSMS Study, Working Paper 35. Washington D.C.: World Bank. 
EDWARDS L.N., and M. GROSSMAN (1977). “An Economic Analysis of Children's Health and Intellectual Development". National Bureau of Economic Research Working Paper 180.

Friedman B., and A. Leibowitz (1975). "The Bequest Motive in Human Capital and the Health Care of Children". Unpublished paper.

Gertler, P., L. LOCAY, and W. SANDERSON (1987). "Are User Fees Regressive?" Journal of Econometrics 36: 67-88.

Gertler, P., and J. VAn der GaAg (1988). Measuring the Willingness to Pay for Social Services in Developing Countries. LSMS Working Paper 45. Washington, D.C.: World Bank.

(1990). The Willingness to Pay for Medical Care: Evidence from Two Developing Countries. Washington, D.C. and Baltimore: World Bank and Johns Hopkins University Press.

Goldman, F., and M. Grossman (1978). "The Demand for Pediatric Care: An Hedonic Approach". Journal of Political Economy 86: 259-80.

Grossman, M. (1972a). The Demand for Health: A Theoretical and Empirical Investigation. National Bureau of Economic Research Ocassional Paper 119. New York.

(1972b). "On the Concept of Health Capital and the Demand for Health". Journal of Political Economy 80: 223-55.

HeLLER, P.S. (1976). "A Model of the Demand for Medical and Health Services in West Malaysia". Discussion Paper 62. Ann Arbor: Center for Research on Economic Development, University of Michigan.

(1982). "A Model of the Demand for Medical and Health Services in Peninsular Malaysia”. Social Science and Medicine 16: 267-84. 
Holtmann, A.G., and E.O. Olsen, JR. (1976). "The Demand for Dental Care: A Study on Consumption and Household Production". Journal of Human Resources 11: 546-60.

INMAN R.P. (1976). "The Family Provision of Children's Health: An Economic Analysis", in Richard Rosset (ed.), The Role of Health Insurance in the Health Services Sector. New York: National Bureau of Economic Research.

KeSSNER D.M. (1974). "Assesment of Medical Care for Children”. Contrasts in Health Status, vol. 3. Washington: Institute of Medicine.

Lavy, V., and J. Germain (1994). "Quality and Cost in Health Care Choice in Developing Countries". LSMS Working Paper 105. Washington, D.C.: World Bank.

LOHR, K., R.H. BroOK, and C.J. KAMBerg ET AL. (1986). "Use of Medical Care in the Rand Health Insurance Experiment: Diagnosis and Service Analyses in a Randomised Controlled Trial”. Medical Care 24 (9), Supplement.

MaKhlouf, K. (1996). "Factores no Monetarios en la Demanda por Servicios de Salud: El Caso de los Controles Preventivos en Chile". Revista de Análisis Económico. Vol 11 (2): 125-154. ILADES/Georgetown University.

MuchniK, E., and I. VIAL (1990). "Impacto del P.N.A.C. en Preescolares de Santiago". INTA, Universidad de Chile.

Musgrove, P. (1983). "Family Health Care Spending in Latin America". Journal of Health Economics 2: 245-57.

Mwabu, G. (1986). "Health Care Decisions at the Household Level: Results of Health Survey in Kenya". Social Science and Medicine 22 (3): 31319. 
(1988). "Conditional Logit Analysis of Household Choice of Medical Treatment in Rural Villages in Kenya". Kenyatta University, Department of Economics, Nairobi.

Mwabu, G., M. Ainsworth, and A. Nyamete (1994). "Quality of Medical Care and Choice of Medical Treatment in Kenya". Journal of Human Resources 28 (4): 832-862.

Newhose, J.P., and C.E. Phelps (1974). "Price and Income Elasticities from Medical Services”. Paper R-1197-NC/OEO. Santa Monica, CA: Rand Corporation.

(1976). "New Estimates of Price and Income Elasticities of Medical Services", in R.N. Rosett (ed.), The Role of Health Insurance in the Health Services Sector. National Bureau of Economic Research Conference Series 27. New York.

PhelPS, C.E., and J.P. Newhouse (1974). "Coinsurance, the Price of Time, and the Demand for Medical Services". Review of Economics and Statistics 56: 334-342.

PAULY, M.V. (1978). "Doctors and Their Workshops: Physician Influences on the Use of Medical Resources". Unpublished manuscript.

POPKIN, B.M. (1974). "Vitamin A Deficiency in the Philippines: The Development and Analysis of Alternative Interventions". Unpublished thesis. Cornell University. Ithaca, New York.

Popkin, B.M., and F. SolON (1976). "Income, Time, the Working Mother and Child Nutriture". Journal of Tropical Pediatrics and Environmental Child Health 22: 156-166.

Rosset, R.N., and L-F HUANG (1973). "The Effect of Health Insurance on the Demand for the Medical Care". Journal of Political Economy 81: 281-305. 
SCARPACI, J.L. (1989). Salud y Regimen Militar. Imprenta La Unión, Santiago, Chile.

SLeSINGER, D.P. (1976). "The Utilisation of Preventive Medical Services by Urban Black Mothers", in David Mechanic (ed.), The Growth of Bureaucratic Medicine: An Inquiry into the Dynamics of Patient Behavior and the Organisation of Medical Care. New York: WileyInterscience.

Torche, A., H. Amigo, E. Atalah, E. Muchnik, and I. Vial (1995). Estudio de Evaluación Económica del Programa Nacional de Alimentación Complementaria, PNAC. Ministry of Health of Chile and World Bank.

VAN DE VEN, W., and J. VAN DER GAAG (1982). "Health as an Unobservable: A MIMIC Model of Demand for Health Care". Journal of Health Economics 1: 117-215.

Wedig, G.J. (1988). "Health Status and the Demand for Health. Results on Price Elasticities”. Journal of Health Economics 7: 151-163. 